\title{
Erratum to: Save 100 Babies $\odot$ : Engaging Communities for Just and Equitable Birth Outcomes Through Photovoice and Appreciative Inquiry
}

\author{
Fleda Mask Jackson • Ama R. Saran • \\ Sharon Ricks • Joyce Essien • Kevin Klein • \\ Darryl Roberts $\cdot$ Natasha Worthy
}

Published online: 4 July 2014

(C) Springer Science+Business Media New York 2014

\section{Erratum to: Matern Child Health J \\ DOI 10.1007/s10995-014-1436-9}

The original publication of the article was submitted and published with a few errors which have been corrected with this erratum.

In the "Abstract," the text "The goal of the conference was to facilitate higher level consciousness by guiding the participants though a process aimed at articulating assets, possibilities and the potential for co-creating the desired future where racial disparities in birth outcome are eliminated." should read correctly as "The goal of the conference was to facilitate higher level consciousness by guiding

The online version of the original article can be found under doi:10.1007/s10995-014-1436-9.

F. M. Jackson $(\bowtie)$

Psychology Department, Spelman College, Atlanta, GA, USA

e-mail: fledamjackson@gmail.com

F. M. Jackson

Save 100 Babies, Atlanta, GA, USA

\section{A. R. Saran}

National Center for Health Behavioral Change, Morgan State University, Baltimore, MD, USA

e-mail: ama.saran@yahoo.com

\section{S. Ricks}

U.S. Department of Health and Human Services, Region IV, Atlanta, GA, USA

e-mail: Sharon.Ricks@hhs.gov

J. Essien

Rollins School of Public Health, Atlanta, GA, USA

e-mail: jessien@emory.edu the participants though a process aimed at articulating assets, possibilities and the potential for co-creating the desired futures where racial disparities in birth outcomes are eliminated."

Under the section "Discussion," the text "It was through the iterations of the AI questioning, moving from discovery through to delivery, provided a pathway for participants might to envision how they might contribute." should now read correctly as "It was through the iterations of the AI questioning, moving from discovery through to delivery, that provided a pathway for participants to envision how they might contribute."

\footnotetext{
K. Klein

Uncharted Territories, Asheville, NC, USA

e-mail: uncharteredterritories@mac.com

D. Roberts

Mt Welcome Baptist Church, Decatur, GA, USA

e-mail: darryldroberts@gmail.com

N. Worthy

Atlanta Healthy Start, Center for Black Women's Wellness,

Atlanta, GA, USA

e-mail: NWorthy@cbbw.org
} 